\title{
Eradication of endophytes from needles, their inoculation with Lophodermium piceae and persistence of this fungus in needles of Norway spruce
}

\author{
Michael M. Müller ${ }^{1}$ (D) . Leena Hamberg ${ }^{1}$
}

Received: 18 January 2021 / Revised: 28 May 2021 / Accepted: 6 June 2021

(c) The Author(s) 2021

\begin{abstract}
Lophodermium piceae is the most common endophyte of Norway spruce (Picea abies) needles, and it probably occurs in the total distribution area of Norway spruce. Its significance to the host tree is still largely unknown mainly because no methodology is known for generating endophyte-free saplings nor for inoculation of intact needles with this fungus. We report here how a daily heat treatment at $40^{\circ} \mathrm{C}$ for $8 \mathrm{~h}$ eradicates endophytes of Norway spruce needles within a few days without causing visible harm to the plants. We compared various methods for inoculation of endophyte-free saplings. In order to obtain effective inocula, we investigated what factors activate dormant $L$. piceae infections in the needle tissue resulting in ascomata formation. Best inoculation success was achieved by suspending naturally shed, highly infected needles above the saplings. Infection frequencies of up to $70 \%$ of needles were achieved with repeated inoculations in the course of 3 years. Once established in needles, individual infections by $L$. piceae can persist for at least 5 years. Individual infections remain small in young needles, but at a needle age of 6 years, they start to grow and spread resulting in presence all over the needle from base to tip at a needle age of 7 years, but still without causing visible symptoms on the needles. The presented methodology for generating both endophyte-free and endophyte-infected saplings of Norway spruce provides a new approach for testing the significance of infections by $L$. piceae to insect herbivory and diseases of Norway spruce needles.
\end{abstract}

Keywords Antagonism $\cdot$ Fungi $\cdot$ Herbivory $\cdot$ Inoculation $\cdot$ Dormancy

\section{Introduction}

Norway spruce (Picea abies (L.) Karst.) is a major coniferous tree species of the Eurasian boreal forests. Its needles are long-lived, typically green and healthy looking for over 5-13 years before they are shed (Schütt et al., 2006). Soon after flushing in spring, the new needles may be colonized with the first endophytic fungi but high colonization frequencies are attained after several years when high proportions, even over 90\%, of the needles have been infected (Barklund 1987; Sieber 1988; Müller and Hallaksela, 1998; Lehtijärvi and Barklund, 2000). Lophodermium piceae (Fuckel) Höhn. is the most common needle endophyte of Norway spruce

Section editor: Marc Stadler

Michael M. Müller

micms.muller@gmail.com

1 Natural Resources Institute Finland (Luke), Bioeconomy and Environment, P.O. Box 2, 00791 Helsinki, Finland needles constituting generally more than $90 \%$ of endophytic isolates obtained from the needles (Sieber, 1988; Müller and Hallaskela 1998). L. piceae has been found also in needles of Abies alba (Gourbière 1988; Minter 1994) and needles of Scottish P. sitchensis (Stewart et al., 2019). This fungus probably occurs in the whole distribution area of Norway spruce throughout Eurasia (Müller et al., 2019).

Individual infections are small and exist inside the needle mesophyll both intercellularly and intracellularly (Suske and Acker, 1987, 1989). Up to 34 individual infections have been observed in single green intact needles (Müller et al., 2001). Small size of the individual infections suggests existence of a dormant mode. Dormancy ends and hyphal growth continues at latest when the needle is shed and turns brown. At this time, fungal individuals start to compete for the needle substrate, and in order to succeed in the competition, L. piceae forms visible dark zone lines in the needles to prevent fungal competitors from approaching (Stephan and Osorio, 1994). These zone lines (or zone discs) are highly resistant to decomposition 
and have been used for enumeration of past presence of $L$. piceae in the needle litter otherwise largely decomposed (Jasinski and Payette, 2005). Under favourable conditions, L. piceae forms tiny ascocarps called hysterothecia which liberate ascospores into the air. The ascospores can be spread by air up into the forest canopy where they infect spruce needles at which point the life cycle of this fungus is completed. In Germany, maximal ascospore discharge coincides with the flushing of new spruce needles from the end of April to June (Osorio and Stephan, 1991).

L. piceae is generally not pathogenic to its host, i.e. it does not trigger premature needle cast (Barklund 1987; Sieber 1988). Whether it has any significance to its host is so far unknown. As a primary decomposer of the needle litter, it may accelerate decomposition of shed needles and thereby speed up liberation of nutrients to be taken back up by nearby trees (Gourbière 1988; Müller et al., 2001).

The lifestyle of $L$. piceae existing in high numbers of tiny symptomless infections within needles of all ages resembles that of Rhabdocline parkeri, a needle endophyte of Douglas fir (Pseudotsuga menziesii). R. parkeri is known to antagonize gall midges by colonizing emerging galls and causing mortality among the midge larvae (Carroll 1988, 1995). It can be speculated that also L. piceae could protect its host against needle herbivory. Production of secondary metabolites by $L$. piceae has not been investigated but other species of the same genus are known to produce several compounds with antifungal activity (Sumarah et al., 2011; McMullin et al., 2018).

Interestingly, Livsey and Barklund, (1992) observed fruiting of $L$. piceae at significantly lower frequency on fallen Norway spruce needles injured by insects than on noninjured needles. Antagonism towards needle pathogens is also possible (Oliva et al., 2020). However, Lehtijärvi et al., (2001) did not find any difference in the frequency of $L$. piceae infections between Chrysomyxa abietis-infected (a needle rust) and non-infected needles of Norway spruce. This suggests that $L$. piceae does not act antagonistically towards this rust.

Interpretation of field observations of differences in endophyte frequencies of insect-damaged or pathogen-attacked needles compared to frequencies in intact undamaged needles is not unequivocal because of lack of knowledge of the endophyte frequency in the needles prior to insect damage or pathogen attack. Experiments exposing both endophyteinhabiting and otherwise corresponding but endophyte-free plants (preferably of the same clone) to a herbivore or disease agent would be ideal for disclosing antagonistic effects possibly caused by endophytic fungi. Lack of methodology for production of Norway spruce saplings with endophytefree needles (Sieber 2007) and lack of an effective methodology for inoculation with L. piceae (Dotzler 1991) has prevented such experiments.
Artificial inoculation of conifer needles with endophytic fungi is possible in the case of several fungal species using spores produced in pure cultures or using macerated hyphal suspensions (Ganley et al., 2008). However, inoculation with water suspensions of $L$. piceae ascospores has been ineffective (Dotzler 1991). It is technically possible to inoculate spruce shoots with fungal propagules also by direct injection into the shoot with a syringe (wound inoculation) expecting that the fungus grows through the petiole into the needle, but this is extremely laborious and has in the case of an endophytic fungus of needles of white spruce (Picea glauca) resulted in only low infection frequency (Sumarah et al., 2005).

Nevertheless, a reduction of budworm performance could be observed in shoots of white spruce wound inoculated with Phialocephala scopiformis compared to control trees (Quiring et al., 2019a). Noteworthy, this result was obtained years after inoculation and at field conditions where endophytic infections by ambient fungi of neither inoculated nor control trees was prevented. This may be a special case and detection of any antagonistic effects caused by an inoculated endophytic fungus is probably more feasible when infections by other ambient fungi can be excluded, both in inoculated and control trees.

The lifespan of individual endophytic infections by $L$. piceae has so far been unknown. No seasonal declines of endophytic infection frequencies were perceived by Barklund (1987) while Sieber (1988) observed considerable seasonal fluctuation of the infection frequency by endophytic fungi in Norway spruce needles suggesting that infections are not long-lived. Ample research on P. scopiformis, an endophyte of white spruce shoots and needles, has provided indications that this fungus could persist for years after wound-inoculation into its host (Frasz et al., 2014; Quiring et al., 2019b). In studies with inoculated saplings, it is important to know how persistent the endophytic infections in needles are; how soon experiments should be carried out after inoculation; and, moreover, can infection frequencies be boosted with repeated inoculations for several years.

Production of endophyte-free conifer saplings from surface-sterilized seeds is possible under axenic conditions (Sumarah et al., 2005) but saplings lacking any other microbes, like for instance root associated ones, may react differently to endophytic inoculation and herbivory than saplings with an otherwise intact diverse microbial flora in their roots and shoots. Using non-sterile growth media and semisterile greenhouse conditions for cultivation of seedlings from surface-sterilized seeds can still result in undesirable infections of the foliage with endophytic fungi, albeit at low frequency (Ganley et al., 2008).

The aims of this study were to generate Norway spruce saplings devoid of needle endophytes and to find a method for inoculation of endophyte-free saplings with $L$. piceae 
for investigations on the significance of $L$. picea to its host. The research reported here included the following parts: (1) eradication of all endophytes from Norway spruce needles without affecting vitality of the host; (2) comparison of three methods for inoculation of endophyte-free needles with $L$. piceae: (a) using ascospore suspensions (requiring study into ascoma maturation) and (b) providing needle litter rich in $L$. piceae infections below or (c) above the saplings; (3) determination of how persistent the infections of $L$. piceae are and if dormancy of the infections ends before needles are shed.

\section{Material and methods}

\section{Eradication of needle endophytes}

Heat treatment Eradication of needle endophytes was attempted by heating Norway spruce saplings repeatedly in growth chambers. In a preliminary experiment, two 5-yearold healthy-looking saplings were dug up with their roots from a spruce forest nearby Helsinki (Paippinen, Sipoo) in September 2005 and planted into 5-L plastic pots with the initial forest soil attached to the roots and filled up with highly humified peat resulting in a ratio of forest soil to peat to approximately 1:1. The saplings were placed outdoors until onset of the experiment 2 months later. The experiment started by enclosing each sapling pot (including stem base and roots) into an EPS-box (expanded polystyrene) in order to protect roots from high temperature during heat treatments of the shoots. The lid of the box had a small hole corresponding to the sapling stem diameter. The saplings were incubated in a Termaks, KB8400L, growth chamber daily for $8 \mathrm{~h}$ at $40{ }^{\circ} \mathrm{C}$ in light $\left(15-25 \mu \mathrm{mol} \mathrm{m}{ }^{-2} \mathrm{~s}^{-1}\right)$ and for $16 \mathrm{~h}$ at $8{ }^{\circ} \mathrm{C}$ in darkness. In this first heat treatment experiment, saplings were heated $8 \mathrm{~h}$ per day for 14 days and in the later inoculation experiments $8 \mathrm{~h}$ per day for 7 days. Soil temperature within the EPS boxes did not exceed $20^{\circ} \mathrm{C}$. Relative air humidity varied from $10-20 \%$ at $40{ }^{\circ} \mathrm{C}$ to $25-35 \%$ at $8{ }^{\circ} \mathrm{C}$. The heat treatment procedure described above was applied later to 18 other saplings and its suitability was tested, as described under the "Inoculation with needle litter spread below spruce saplings" subheading.

Needle sampling Before and after heat treatment, endophyte presence was investigated from detached needles. Needles of different age classes were treated separately. Current year needles were considered to represent age-class 1 and needles attached to twig segments below the first set of terminal bud scars were considered as age class 2 needles and the next set as age class 3 and so on. Needles were sampled for isolation of endophytic fungi seven times during the experimental time of 14 days. In each time, five needles of both age classes 3 (flushed in 2003) and 4 (flushed in 2002) were removed from each sapling (in total 20 needles per date). Only these age classes were investigated because they were the two oldest age classes providing high enough numbers of needles needed for repeated sampling and because they were presumed to inhabit endophytes at higher frequency than needles of the two younger age classes. Needles were sampled and analyzed for endophyte presence also in some other experiments of this study, and the sampling protocols applied are explained in the descriptions of those experiments.

Determination of endophytic infection frequency Endophytic fungi, including Lophodermium piceae, were isolated from Norway spruce needles after surface sterilization with sodium hypochlorite as described by Müller and Hallaksela, (1998). The needles were then cut into ca. 2-mm sections (i.e., a piece of needle cut orthogonally to the needle longitudinal direction) which were pushed into water agar in petri dishes (diam. $9 \mathrm{~cm}$ ). After 4 weeks, incubation at $20^{\circ} \mathrm{C}$ endophytic presence was noted as fungal growth from individual needle sections on the water agar plates.

\section{Comparison of three methods to inoculate spruce saplings}

Ascospore suspension Inoculation of Norway spruce saplings was first tried with ascospores obtained from shed needles collected under mature trees in Paippinen, Sipoo in southern Finland (sampling area P, described by Müller and Hallaksela, 1998). The needles were collected using a nylon net $(1 \times 2 \mathrm{~m}$, mesh size $1 \times 2 \mathrm{~mm})$ (see illustration in the Online Resource 1, Fig. 1a). The net was laid on the ground in May 2005, and 4 months later, all needles fallen on the net were removed and checked for mature ascocarps of L. piceae.

Because only few mature ascocarps were found on the needles, we incubated the collected needles under various conditions in order to find out how the development of ascocarps of L. piceae could be triggered. The needles were separated into four groups: (1) green, (2) brown without zone lines or spots, (3) brown with zone lines but without black spots and (4) brown with black spots and with or without zone lines. Additionally, green symptomless needles of age class 5 were removed from eight trees in the Norway spruce forest in Paippinen. The detached needles formed the fifth needle group. After separation into five groups, the needles were stored at $0{ }^{\circ} \mathrm{C}$ for 4 months and then used in an experiment in which the needles were incubated in three different conditions. The incubation was carried out in 45 transparent polypropylene containers $(12 \times 12 \times 10 \mathrm{~cm}$, width $\times$ length $\times$ height $)$ (Sterivent, 
Duchefa Biochemie, Netherlands) filled first with $200 \mathrm{ml}$ of sand (grain size $<2 \mathrm{~mm}$ ) on the bottom and thereafter with $1 \mathrm{dl}$ of spruce forest humus. The humus and sand were moistened with deionized water to field capacity; whereafter, $10 \mathrm{ml}$ of water was added. Each of the five needle types were divided into six to fourteen containers (number varied according to availability of each needle class among needles obtained on the nylon net) including 96 to 500 needles per container. Then, the containers were closed with nearly airtight lids and incubated in growth chambers (Termaks, KB8400L) in three different ways. Two to five containers per needle type were allocated to each of the following treatment:

1. Under visible and UV-light at $5{ }^{\circ} \mathrm{C}$ for 4 days and at $0.2{ }^{\circ} \mathrm{C}$ in darkness for 3 days each week. Light intensity was $15-20 \mu \mathrm{mol} \mathrm{m}{ }^{-2} \mathrm{~s}^{-1}$ of which approximately $1 / 3$ was in the ultraviolet range.

2. No light but otherwise similar conditions as in treatment 1.

3. Temperature continuously at $15^{\circ} \mathrm{C}$ and light as in treatment 1 for $9 \mathrm{~h}$ per day.

Moisture was added weekly to retain the initial weight of each jar. Needles with ascocarps of $L$. piceae were counted and removed six times during 250 days. Needles with high numbers of ascocarps were stored at $+0{ }^{\circ} \mathrm{C}$ until ascospore extraction 4 days later. Ascospores were extracted by immersing 60 needles, each having at least 2 mature (i.e. opened when wetted) ascocarps, into $100 \mathrm{ml}$ of $0.2 \% \mathrm{NaCl}-$ $\mathrm{H}_{2} \mathrm{O}$ and by sonicating this for $1 \mathrm{~min}$. This resulted in a suspension with $83 \times 10^{3}$ ascospores per $\mathrm{ml}$ (determined with a Bürker counting chamber).

Twenty millilitres of this suspension was sprayed within the same day when prepared (in June 2006) on two endophyte-free 6-year-old spruce saplings. These saplings had been dug up with their roots from a mature spruce stand nearby Helsinki (Paippinen, Sipoo) in the previous year, transplanted into 5-L containers, heat-treated and placed outdoors. Heat treatment was carried out by heating the saplings during 7 days for $8 \mathrm{~h}$ per day in order to eradicate needle endophytes as described previously in the "Heat treatment" section. Each sapling was covered with a polyethylene $(0.25 \mathrm{~mm})$ bag to prevent access by spores occurring in ambient air (illustrated in the Online Resource 1, Fig. 1b). Prior to inoculation, 8 needles were randomly removed and weighted before and after wetting which revealed an average retention of $2.2 \mu \mathrm{g}$ water per needle. This means that wellwetted needles were able to retain up to 183 ascospores per needle. Just before and 2 months after inoculation, the endophyte infection frequency was determined from the three latest needle age classes. For this purpose, six needles per age class (1, 2 and 3), sapling and sampling date (6 needles $\times 3$ age classes $\times 2$ saplings $\times 2$ sampling dates, i.e. in total 72 needles) were randomly removed. Their endophytic infection frequency was determined as described previously in the "Determination of endophytic infection frequency" section.

Inoculation with needle litter spread below spruce saplings In this field experiment, eighteen Norway spruce saplings representing three clones T4658, T4748 and T5134 were cultivated outdoors covered with polyethylene bags for 4 years as described in detail below.

The saplings were derived from rooted cuttings that were generated by cutting ca. 8-cm-long twig tips from 5 -yearold Norway spruce plantlets in February 2006 and cultivated in a mixture of peat and vermiculate at $90-100 \%$ air moisture for the first 2.5 months and thereafter outdoors. At the beginning of the experiment in 2008, the saplings were ca. $20 \mathrm{~cm}$ high and their needles contained endophytes at a low frequency of $2-18 \%$, depending on the clone. Therefore, the saplings were first heat-treated (during 7 days for $8 \mathrm{~h}$ per day) in order to eradicate the endophytic fungi using the method described in the "Heat treatment" section. After the heat treatment, needles were sampled ( 3 needles per age class including age classes 1, 2 and 3 and per sapling, i.e. in total $3 \times 3 \times 18=162$ needles) and examined for endophytic presence (as described in the "Determination of endophytic infection frequency" section) to ensure that endophytes were eradicated. Then, the saplings were transplanted in six groups (each consisting of three saplings, one for each clone) into a shady garden site in Helsinki in October 2008. Each group of three saplings was confined within a $50 \times 40 \times 80 \mathrm{~cm}$ (width $\times$ length $\times$ height) wooden structure and covered with a polyethylene bag to prevent access by spores possibly driven by the ambient air (as illustrated in the Online Resource 1, Fig. 1b).

Three sapling groups, each including three different spruce clones (i.e. in total nine saplings) were subjected to inoculation with needle endophytes using shed needles collected from the ground of a mature Norway spruce stand. Another similar set of three sapling groups served as controls for the inoculation. The needles used for inoculation were collected with two nylon nets $(1 \mathrm{~m} \times 2 \mathrm{~m}$, mesh size $0.2 \mathrm{~mm}$ ) placed on the forest ground of a mature spruce stand in Paippinen, Sipoo (nearby Helsinki) in November 2008. The needles were removed from the nets in the beginning of May 2009, cleaned from other litter and placed on the ground below the saplings ( 11 of needles per each group of three saplings). The needles were wetted with tap water every fortnight from May to July.

In November 2009, needles of each of the age classes 1, 2 and 3 were sampled from the inoculated spruce saplings 
(three needles per age class and sapling, i.e. 3 needles $\times 3$ age classes $\times 3$ saplings per group $\times 3$ sapling groups, i.e. in total 81 needles) for determination of inoculation success as described previously in the "Determination of endophytic infection frequency" section.

Inoculation with needle litter placed above spruce saplings This experiment was started after the previous trial (in which needles were spread below the saplings) using the same saplings. All needles below the saplings were removed and "new" needle litter collected under mature spruces from November 2009 to May 2010 and suspended on a metal sieve (mesh size $5 \mathrm{~mm}$ ) immediately above the saplings at the end of May (as illustrated in the Online Resource 1, Fig. 1c). The needles were wetted with tap water 2 times a week until July.

Infection frequency was determined in November 2010 from 81 needles sampled similarly as described for the previous sampling in 2009. Inoculation showed to be successful because $34-56 \%$ of needles of age classes 1, 2 and 3 were infected. In order to achieve a higher infection frequency, this inoculation procedure was repeated by replacing the previous year brown needles collected for inoculation with newly collected ones in May 2011 and May 2012. In November 2012, needles of age classes 1 to 4 were again sampled from the saplings ( 3 needles $\times 4$ age classes $\times 3$ saplings per group $\times 3$ sapling groups $\times 2$ treatments, i.e. in total 216 needles) and investigated for their endophytic infection frequency as described in the "Determination of endophytic infection frequency" section.

Identification of $L$. piceae In the third inoculation experiment (needle litter suspended above spruce saplings), all fungal colonies noted during determination of the endophytic infection frequency in 2012 were isolated and a batch of 30 randomly selected isolates was subjected to identification based on ITS-sequences.

Single hyphal tips from colonies that emerged into water agar from the needle sections (when assessing endophytic infection frequency) were removed with a modified Pasteur pipette and transferred to fresh orange serum agar plates (MOS-agar; Müller et al., 1994). After a 3-4-week cultivation, small agar blocks were cut from each colony edge and transferred into 2-ml cryogenic vials (Nalgene, Merck, Germany) and stored at $6{ }^{\circ} \mathrm{C}$. Later, thirty fungal isolates were randomly selected and cultivated on MOS-agar covered with a cellophane membrane (diameter $8 \mathrm{~cm}$, British Cellophane Ltd., UK) for 2 weeks at $20^{\circ} \mathrm{C}$ after which mycelial samples were removed from colony edges and stored at $-20{ }^{\circ} \mathrm{C}$ for DNA extraction. DNA extraction, PCR and sequencing have been described previously (Müller et al., 2007). Isolates with $\geq 98 \%$ sequence similarity with Finnish $L$. piceae isolates (described by Müller et al., 2007) were identified as L. piceae.

The colony morphology of all isolates, identified as $L$. piceae based on their ITS-sequences, corresponded to that of isolates identified by their morphological, chemotaxonomical and genetic characteristics in our previous studies (Müller and Hallaksela, 1998; Müller et al., 2007). The following characteristics of colony morphology, typical for L. piceae on MOS-agar, were used for backing up the molecular identification: slow growth that always ceases before the edge of the dish is reached, colony appearance compact and chewy with a wrinkled or lumpy surface, colony edge uneven, no spore formation and colour highly variable between isolates.

\section{Persistence of needle endophytes in Norway spruce}

Persistence of needle endophytes, their occurrence in adjacent needle sections, and the ability of endophytes to grow further within a needle when ageing was investigated by following the endophytic infection frequency for 6 years in needles of saplings protected with plastic bags against further infections by airborne spores as described in detail below.

Five 5-year-old saplings were dug up with their roots from a mature spruce stand near Helsinki (Paippinen, Sipoo) and transplanted in July 2007 into a shady garden site and confined within polyethylene bags (height $1 \mathrm{~m}$, diam. $39 \mathrm{~cm}$, as illustrated in the Online Resource 1, Fig. 1b) in November 2007. Temperature was followed within the bags with a minimum-maximum thermometer. The air temperature never exceeded $28^{\circ} \mathrm{C}$ within the polyethylene bags.

Ten needles of those flushed in 2005, as well as ten needles of each of the later age classes, were sampled from each sapling annually in November (from 2007 to 2012) and investigated for endophytic infection frequency after surface sterilization as explained previously in the "Determination of endophytic infection frequency" section. Each colony emerging in water agar from the $2-\mathrm{mm}$ needle sections was recorded according to sapling, needle and needle section to enable keeping track of their initial position along a single needle so that it was later possible to recognize infections occurring in adjacent needle sections. The needle length varied from 6 to $20 \mathrm{~mm}$. All fungal colonies noted during determination of the endophytic infection frequency of needles that were obtained in the last sampling (in 2012) were isolated. From these isolates, 50 were randomly selected for DNA-extraction and sequencing of the ITS-region in order to determine the occurrence of $L$. piceae (as described in the "Identification of L. piceae" section).

The polyethylene bags did not completely prevent new endophytic infections to emerge in needles since later, some infections were found in needles of 2008 that developed after confining the saplings into bags (data are given in the "Results" section). We assume that older needles became 
infected by contaminants at a similar intensity as needles of 2008 and subtracted from their infection frequency that observed in needles of 2008 .

\section{Statistical analyses}

Results from the eradication experiment of endophytes from spruce needles and from inoculation experiments of spruce needles with $L$. piceae are reported with figures and in text without statistical analyses. Results from experiments on the persistence of endophytic infections, their occurrence in adjacent needle sections and the ability of endophytes to grow further within a needle when ageing were investigated using statistics described below.

Changes in infection frequencies of $L$. piceae in needles during the persistence experiment were investigated as follows. First, the infection percentages were corrected for unexpected contamination during the experiment by subtracting the infection percentage found annually in needles of age class 2008 from the respective results obtained for needles of previous age classes 2005, 2006 and 2007. Then, endophytic infection percentages determined annually (until 2012) were compared to results obtained in the first year (2007 or 2008, depending on needle age class) within each age class separately $(n=22$ for the needle age class 2005 , $n=29$ for the age class 2006 and $n=24$ for the age class 2007) using linear mixed models (LMMs). Function lme in library nlme in the statistical programme $\mathrm{R}$ was used ( $\mathrm{R}$ Core Team 2017; Pinheiro et al., 2017). The percentage values were logit-transformed for model estimations (Warton and Hui, 2011). Thus, the transformed proportion of needle sections infected was used as a response variable, and as an explanatory variable, we had the sample year (a factor with six levels: 2007, 2008, 2009, 2010, 2011 and 2012, excluding 2007 for needle age class 2007). As a random factor, we had a spruce sapling. Random factor takes into account the fact that needles collected from the same sapling are more similar than observations from randomly collected saplings and needles.

Furthermore, we estimated a generalized linear mixed model (GLMM) to investigate whether the occurrence of adjacent infections (described in the "Persistence of needle endophytes in Norway spruce" section) within a needle increases with needle age, i.e. do individual infections grow with time and occupy a larger portion of aged needles compared to infections in young ones. Only needles with two sections infected were included in the analyses (in total 94 needles) in order to avoid a bias potentially caused by unwanted contaminations during the experiment. The model was estimated using function glmer in library lme4 in R (binomial distribution with logit link function, R Core Team
2017; Bates et al., 2015). As a response we had the occurrence of an endophyte in adjacent needle sections (a factor with two levels: $0=$ no endophyte exists in adjacent needle sections, $1=$ endophytes existed in adjacent needle sections), and as explanatory variables, we had (1) needle age in years $(x-\operatorname{average}(x)),(2)$ squared needle age $\left((x-\text { average }(x))^{2}\right)$, (3) cubic needle age $\left((x-\operatorname{average}(x))^{3}\right)$ as we assumed a curvilinear response and (4) the number of needle sections investigated per needle. Explanatory variable 4 was included in the model to take into account the fact that the number of needle sections varied from 3 to 6 . As nested random factors, we had the code for saplings and the collection year since we assumed that needles within one spruce sapling and the same collection year are more similar than randomly collected needles. All figures were drawn with Excel software (Microsoft, USA).

\section{Results}

\section{Eradication of needle endophytes}

Repeated daily heat treatment at $40{ }^{\circ} \mathrm{C}$ suppressed the endophytic infection frequency drastically after 5 days and completely after 9 days (Fig. 1). Also, when applied to saplings of two inoculation experiments (with needle litter spread below or above spruce saplings, including 18 saplings), heat treatment before the inoculation proved to work in terms of successful eradication of needle endophytes without discernible harm to the sapling from this treatment.

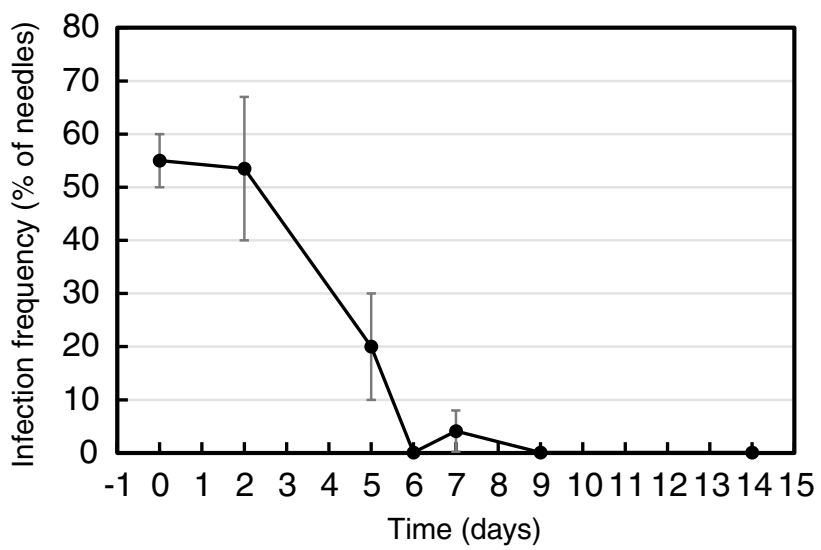

Fig. 1 Suppression of Norway spruce needle endophytes by daily heating at $40{ }^{\circ} \mathrm{C}$ for $8 \mathrm{~h}$ in light. Conditions during the rest of each day: $8{ }^{\circ} \mathrm{C}$ no lights. Each symbol represents the average result of 20 needles (age classes 3 and 4) and the whiskers indicate maximum and minimum values obtained from two saplings 


\section{Comparison of three methods to inoculate spruce saplings}

\section{Production of ascospore suspension and use for inocula-} tion When shed needles were incubated in polypropylene containers at controlled temperature and moisture, ascocarps of $L$. piceae appeared at the highest frequency in initially brown needles with black spots (Fig. 2). Their development was not affected by the use of visible and UV-light. Appearance of ascocarps peaked sharply in these needles at 70 days of incubation at a temperature alternating between 0.2 and $5{ }^{\circ} \mathrm{C}$; whereafter, only a few new ascocarps developed (a result not shown in figures). Ascocarps emerged at lower numbers in initially brown needles with zone lines (but without black spots), brown needles without zone lines or black spots and shed green needles (Fig. 2). Noteworthy, no ascocarps developed on detached green needles during the long incubation period of 250 days even though their endophyte infection frequency was initially $100 \%$ of needles and $82 \%$ of 2-mm needle sections. Inoculation of Norway spruce saplings with an aqueous suspension of $L$. piceae ascospores resulted in a low endophytic infection frequency with only ca. $5 \%$ of needles infected.

Inoculation with needle litter spread below spruce saplings resulted in a low endophytic infection frequency (less than $5 \%$ of needles) in the three youngest needle age classes.

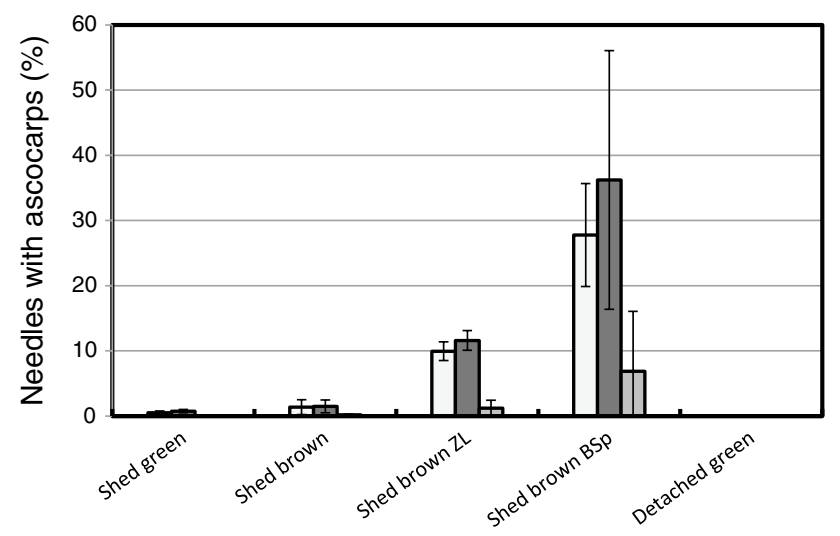

Fig. 2 Emergence of $L$. piceae ascocarps on initially different Norway spruce needles after incubation for 70 days at three conditions: (1) temperature alternating between $0.2{ }^{\circ} \mathrm{C}$ (3 days per week) and $5{ }^{\circ} \mathrm{C}$ in visible and UV-light (4 days per week; white columns), (2) the same temperature conditions as in treatment 1 but without light (black columns) and (3) constantly at $15{ }^{\circ} \mathrm{C}$ in visible and UV-light (grey columns). Shed needles were collected below mature spruce trees and their initial appearance is given below the figure $(\mathrm{ZL}=$ needles with zone lines but without black spots; $\mathrm{BSp}=$ needles with black spots and with or without zone lines). For comparison, intact symptomless green needles (age class 5) were detached from the same trees. Vertical bars indicate standard error of the mean $(n=2-5$ containers, with 97-500 needles in each)
Inoculation with needle litter placed above spruce saplings resulted in an infection frequency of 5-20\%. However, a higher infection level was attempted and therefore this practice was continued during the next 2 years, by replacing the needle litter annually with newly collected ones. This resulted in a high infection frequency by endophytic fungi (Table 1). Needles of age classes 3 and 4 of the control saplings (not exposed to brown needle litter) became infected unexpectedly as well, but at considerably lower frequency. Fifteen out of seventeen fungal isolates obtained in 2012 from the inoculated Norway spruce saplings were identified as $L$. piceae but only two out of thirteen isolates obtained from control saplings proved to be $L$. piceae according to their ITS-DNA sequences.

\section{Persistence of needle endophytes in Norway spruce}

In the outdoor experiment with forest-derived saplings, needle endophytes showed persistence over several years after confinement of the saplings in polyethylene bags (Fig. 3). Needles of 2008 developed after confining the saplings into the bags in 2007 and were therefore supposed to remain free of endophytic needle fungi during the course of this experiment, but the polyethylene bags did not completely prevent new endophytic infections to emerge in these needles. This is indicated in Fig. 3 by a low infection frequency $(<5 \%)$ of these needles during years 2008-2012. There was no significant increase or decrease (LMMs, $p>0.050$ ) in infection frequency of needle age classes 2005, 2006 and 2007 during the course of the experiment compared to their initial infection frequency in 2007 (needle age classes 2005 and 2006) or in 2008 (age class 2007). Based on ITS-sequences, L. piceae was the most frequent species among isolates obtained from needles of these saplings at the end of the experiment in 2012 , i.e. 42 isolates out of 47 (89\%) were identified as $L$. piceae (three sequences obtained from all randomly chosen 50 isolates had low-sequence quality and were removed from

Table 1 Inoculation success with brown needle litter spread on a metal sieve above Norway spruce saplings. Nine saplings were exposed to needle litter in June 2010, 2011 and 2012. Another nine saplings were not exposed (controls) to needle litter. Infection frequency was determined in November 2012 from 27 needles per treatment and age class

\begin{tabular}{llr}
\hline $\begin{array}{l}\text { Needle } \\
\text { Age class/year when flushed }\end{array}$ & \multicolumn{2}{l}{$\begin{array}{l}\text { Endophytic infection frequency } \% \text { of } \\
\text { needles } \pm \mathrm{SE}^{\mathrm{a}}\end{array}$} \\
\cline { 2 - 3 } & Inoculated & Control \\
\hline $4 / 2009$ & $72 \pm 19$ & $29 \pm 13$ \\
$3 / 2010$ & $73 \pm 15$ & $17 \pm 9$ \\
$2 / 2011$ & $37 \pm 18$ & $0 \pm 0$ \\
Current/2012 & $50 \pm 15$ & $0 \pm 0$ \\
\hline
\end{tabular}

${ }^{\text {a }}$ Standard error 

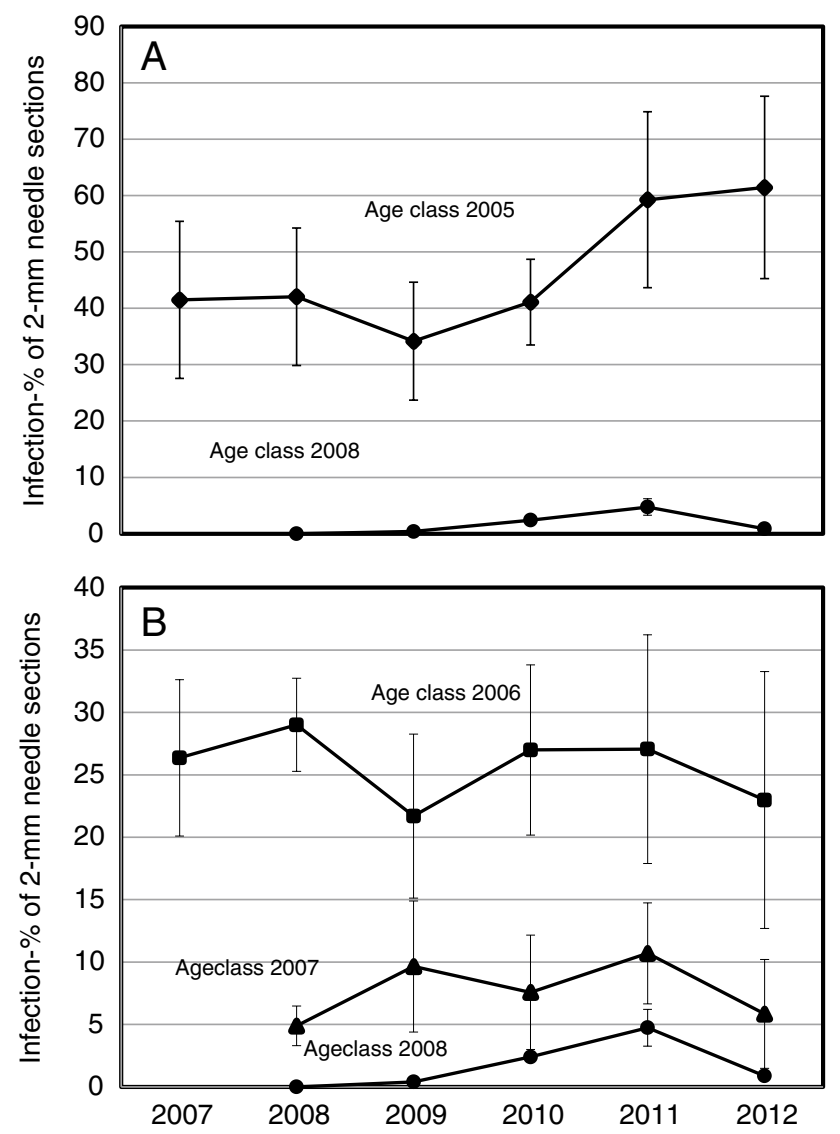

Fig. 3 Persistence of endophytic fungi in needles of five Norway spruce saplings in an outdoor experiment. The saplings were confined in May 2007 within polyethylene bags for preventing access of air-driven ambient fungal spores. Infection percentage by endophytic fungi is shown for clarity in two separate figures: for needles of age classes (i.e. year when flushed) 2005 and 2008 (A), and 2006, 2007 and 2008 (B). Infection percentage found annually in needles of age class 2008 was subtracted from the respective results obtained for needles of previous age classes (because it was considered to represent the level of contamination). Each data point represents results of ca. 50 needles (ca. 250 needle sections) and vertical bars indicate the standard error

the data). ITS-sequences of the remaining 5 isolates (11\%) did not match any species sequences in GenBank.

In order to find out if individual infections grew in the needle with time to appear in more than one needle section, we compared the spatial distribution of infections in needles of various age. To cope with the bias caused by unwanted contaminations of needles during the experiment, we restricted this investigation to needles with two infected sections only. The data included 9, 18, 20, 17, 21 and 9 needles of age classes 1, 2, 3, 4, 5 and 6 , respectively. The proportion of needles with two adjacent infected sections varied during the first 5 years between 51 and $66 \%$, then grew steeply reaching $100 \%$ when the needles became 6 years old (Fig. 4). The data included nine 6-year-old needles, and in

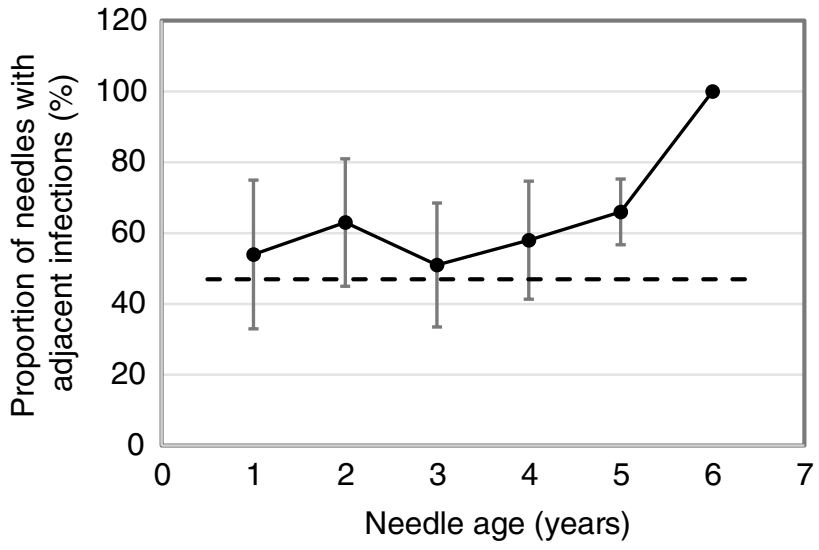

Fig. 4 Proportion of needles with endophytic infections in two adjacent ca. 2-mm-long needle sections (i.e. pieces of needles cut orthogonally to the needle longitudinal direction) among needles with two sections infected. This calculation included 94 needles of five saplings. Vertical bars indicate the standard error. Dashed line indicates the theoretical average value $47 \%$ when infections distribute lengthwise randomly along the needle

all of them, infections were in adjacent sections (i.e. standard error bars are zero in Fig. 4). Seven-year-old needles are missing in this figure because all but one needle of this age had more than two sections infected, and moreover, in $83 \%$ of these needles, an endophytic inhabitant existed in all of their needle sections. Endophytic infections appear to have distributed lengthwise randomly along the investigated needles (Fig. 5). Accordingly, when a needle has already one infection and receives a new detectable infection, then the probability that this appears in a section adjacent to the initially infected section depends on the needle length as follows; $p=0.50$ in 4 -section needles and $p=0.40$ in 5 -section

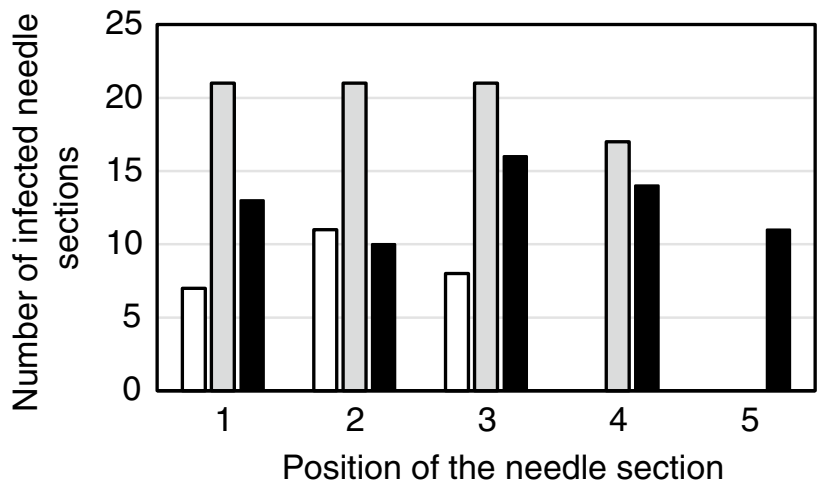

Fig. 5 Distribution of endophytic infections among needle sections (i.e. pieces of needles cut orthogonally to the needle longitudinal direction) of needles including three size classes: 5-7-mm (white columns), 7-9-mm (grey columns) and 9-11-mm (black columns) long needles which resulted in 3, 4 and 5 needle sections (each ca $2 \mathrm{~mm}$ long), respectively. Only needles with two infected sections were included $(n=94)$. Section numbering runs from needle base to tip 
needles. As those needles with two adjacent infected sections consisted in average of 4.4 needle sections, the average probability of two adjacent sections being infected is for this batch of needles ca. 0.47 (calculation is presented in the Online Resource 2). Only 6-year-old needles deviated clearly from this value (Fig. 4). The increase in the occurrence of endophytic infections in adjacent sections from 1 to 6 years old needles was statistically significant ( $p=0.026$ for the squared term in GLMM).

\section{Discussion}

Eradication of Norway spruce needle endophytes with repeated heating at $40{ }^{\circ} \mathrm{C}$ was successful, both in the initial trial including two wild (i.e. forest-derived) saplings (Fig. 1), as well as during preparation of 18 saplings (derived from rooted cuttings) for two inoculation experiments. However, all needle endophytes may not be detected with culturing (Rajala et al., 2013) and the method should be validated using molecular methods enabling detection of possible unculturable fungi. Tolerance of Norway spruce shoots to a temporary elevated temperature of $40{ }^{\circ} \mathrm{C}$ is not surprising, because in summer, for instance in southern Finland, air temperature in the shade annually reaches $30{ }^{\circ} \mathrm{C}$ which means that in direct sunlight, the temperature of needles could then be expected to approach $40{ }^{\circ} \mathrm{C}$ (Gates 1980).

Of the three inoculation trials conducted, best results were obtained using highly infected needle litter collected from a Norway spruce stand under mature trees and suspended above the experimental spruce saplings (Table 1). An infection percentage of $37-73 \%$ of needles is in the range naturally occurring in Norway spruce (Müller and Hallaksela, 1998) and is therefore an acceptable infection intensity for experiments meant to reveal the significance of $L$. piceae to its host. The inoculation using brown needle litter was successful also because the majority of infections (detected later in needles of the saplings) were caused by L. piceae as deduced from the high prevalence of this species in a random sample of isolates identified by their ITS-sequences.

Identification of $L$. piceae based on ITS-sequences can be regarded as reliable in this study because it was backed up by evaluating the colony morphology of each isolate and because the variation of ITS-sequences among Finnish isolates of $L$. piceae is well known from previous studies (Müller et al., 2007). Moreover, only a few species occurring endophytically in needles of Norway spruce dominate which decreases the risk of misidentifications; 6 species covered $95 \%$ of all isolates encountered in a previous comprehensive survey of needle endophytes of Norway spruce in South Finland (Müller and Hallaksela, 1998). Similarly, only 12 species were represented with at least three isolates per 1000 isolates of endophytes derived from Norway spruce needles in a large survey in Switzerland (Sieber 1988).

When aiming to produce ascospores for inoculation purposes, abundant ascocarp development can be expected only in naturally shed brown needles with black spots and/ or zone lines (Fig. 2). Osorio and Stephan, (1991) emphasized the importance of precipitation and high air humidity for the release of ascospores from hysterothecia of $L$. piceae. Humidity in our experimental containers was probably constantly near $100 \%$ because the soil was initially wetted to exceed field capacity and drying was prevented by nearly airtight lids and regular compensation of evaporated moisture.

It is notable that no single ascocarp was observed on over 1000 detached green needles during incubation of 250 days even though $100 \%$ of the needles were initially infected by endophytes. Instead, ascocarps appeared at low frequency (8\%) on naturally shed green ones collected from the ground but the age of these needles is unknown. What factors trigger dormant endophytes to grow and thrive in the host tissue enabling their proliferation? Our results suggest that these factors are age-related, and growth can begin in still attached healthy-looking needles (Fig. 4).

More frequent development of ascocarps at a low temperature of $0.2-5{ }^{\circ} \mathrm{C}$ than at $15{ }^{\circ} \mathrm{C}$ was unexpected when considering earlier field observations described in literature. Osorio and Stephan, (1991) observed the highest ascospore discharge in situ by L. piceae after rainfall in the beginning of June when air temperature varied between 10 and $15^{\circ} \mathrm{C}$. Considerable spore discharge appeared also soon after rainfalls at the end of June when daily temperature varied between 10 and $20^{\circ} \mathrm{C}$.

In Germany, the highest ascospore discharge coincides with flushing of new needles (Osorio and Stephan, 1991) suggesting that flushing needles are the primary infection targets. However, based on previous results, infection frequency by $L$. piceae increases with needle age (Lehtijärvi and Barklund, 2000; Barklund 1987). Thus, not only recently flushed young needles are susceptible to new infections. Therefore, low temperatures during winter and spring may, after all, be more important in ruling the timing of ascocarp development than flushing of new needles. In the present study, the sharp peaking of ascocarp emergence after ca. 70-day incubation may reflect the need of narrow timing which may be crucial in order to liberate ascospores during the short time at the beginning of summer when the risk that the needle surface becomes desiccated prolongedly by frost or high air temperature is low. Simultaneous development of ascocarps may also hamper extended proliferation of ascocarp feeders and parasites. It is also possible that $L$. piceae is more competitive at low temperatures than at high temperatures compared to other needle associated fungi. 
This is the case for instance in comparison to Rhizosphaera kalkhoffii (Scattolin and Montecchio, 2009).

Inability to inoculate Norway spruce needles with an aqueous suspension of $L$. piceae ascospores is in line with the observation of Dotzler (1991) in similar experiments. Dotzler was able to increase inoculation success by surface sterilizing the needles prior to inoculation. A hypochlorite treatment and eradication of epiphytic microbiota from the shoot of a sapling could technically be possible but would perhaps cause unpredictable effects to the saplings.

Air movement within the polyethylene bags was probably very low and may explain why the inoculation success with brown needles spread under the saplings was poor compared to the inoculation success with similar needles when suspended above the saplings.

The needles of heat-treated control saplings in the inoculation experiment with brown needle litter (Table 1) became contaminated during the experimental time of 4 years. Can the unexpected infections (hereon contaminants) be caused by hyphal growth from the twigs or by air-driven spores? If endophytic fungi existing in the twigs of the saplings survived the heating treatment, their penetration into the needles later during the experiment is improbable because endophytic species common in needles occur rarely or are absent in twigs of Norway spruce (Sieber 1989). On the other hand, contamination by soil-borne fungi from below the non-inoculated saplings (within the polyethylene bags) appears to be a more plausible explanation for this observation and is supported by the low frequency of $L$. piceae among isolates (two out of thirteen isolates) obtained in 2012 (4 years after the heat treatment) from non-inoculated control saplings. We cannot, however, exclude the possibility that spores have entered the plastic bags also from the ambient air through possible slits between the plastic bag and the ground. The bag edges were namely not dug into the soil but rested only on the soil. Contamination was observed exclusively in older needles (Table 1), which would not be detrimental to a palatability experiment with those arthropods that feed exclusively on needles of the two youngest age classes (like larvae of many sawflies) which were endophyte-free in the control saplings.

Results from our experiment with saplings confined for several years within plastic bags suggests that individual infections by $L$. piceae can persist for at least 5 years in Norway spruce needles (Fig. 3). This finding is supported by results of Barklund (1987) who observed no seasonal declines in endophyte abundance of Norway spruce needles in Sweden.

Similar to the inoculation experiment discussed above, we noticed in the persistence experiment also some unexpected infections in needles of saplings. These also were confined within the plastic bags that were assumed to prevent contamination with spores driven by the ambient air. The colonization of age class 2008 needles (those needles had never been exposed freely to ambient air) by endophytic fungi (i.e. contamination) can be explained in several ways, three of which were presented above when discussing the inoculation experiment. In this persistence experiment, another, and the most likely, explanation is that some ascocarps developed on needles of earlier age classes and liberated ascospores within the bags (as saplings in this experiment were not heat-treated). The observed contamination was, however, low compared to the initial infection frequencies of older needles flushed in years 2005-2007 (Fig. 3) and does not invalidate the interpretation of this result according to which the life span of individual endophytic infections by $L$. piceae in Norway spruce needles reaches at least 5 years. In future experiments, contamination of control saplings may be prevented by two methodological improvements: (1) by spreading coarse sand on the ground below the saplings to avoid soil borne spores from spreading into the bag air and (2) by placing the polyethylene bag edges into the sand to prevent leakage of ambient air into the bags.

Calculations from data including only needles with infections in two sections suggest that individual endophytic infections remain small (i.e. not reaching from one $2-\mathrm{mm}$ section to another) until the host needle achieves the age of 5 years (Fig. 4). In other words, the rather stable infection percentage observed in needles over the 5-year experimental time of the persistence experiment (Fig. 3) was not a result of the growth of a few individual surviving infections in the needle at the same time when other infections died.

The abrupt increase of the proportion of needles with two adjacent infections when needles exceed the age of 5 years (Fig. 4) cannot be explained by contaminations during the experiment because random infections would not increase the proportion of adjacent sections above ca. $47 \%$ in needles (Online Resource 2). Randomness of endophytic infections along individual needles appears apparent from Fig. 5. Obviously, individual endophytic infections started to grow in needles reaching the age of 6 years with the outcome, just a year later, that endophytic infections were detected in every needle section of nearly all investigated needles. It remained unknown what factor triggered the endophytes to start growing in needles of 6 years of age.

We can suppose that as long as individual infections of $L$. piceae remain dormant and small, their potential to produce metabolites toxic to other invaders or herbivores along the total needle may be low. Antagonistic effects can arise, besides from production of various toxins, also from competitive exclusion of key metabolites as demonstrated for pine shoot endophytes towards the pathogenic fungus Diplodia sapinea (Oliva et al., 2020). Regardless of the antagonistic mechanism or target organism, the methodology presented here for generating both endophyte-free and endophyte-infected saplings of Norway spruce provides a 
new approach for testing the significance of infections by L. piceae, for example, to herbivory of needles and to needle diseases of Norway spruce. Perhaps this methodology is applicable also to other conifer species.

Supplementary Information The online version contains supplementary material available at https://doi.org/10.1007/s11557-021-01714-8.

Acknowledgements We thank Sirkku Pöykkö for providing rooted cuttings of Norway spruce for this study and Juha Puranen is acknowledged for skillful technical help. Kiti Müller is acknowledged for a linguistic check of the manuscript. We thank also two anonymous reviewers for valuable comments and suggestions which helped to improve the manuscript.

Author contribution Michael Müller was responsible for the study conception and design. Statistical data analysis was performed by Leena Hamberg. The first draft of the manuscript was written by Michael Müller, and Leena Hamberg commented on all versions of the manuscript. Both authors read and approved the final manuscript.

Funding Open access funding provided by Natural Resources Institute Finland (LUKE). This research was financed by the employer institute (Luke).

Data availability The datasets generated and analyzed during the current study are available from the corresponding author on reasonable request.

Code availability Not applicable.

\section{Declarations}

Ethics approval Not applicable.

Consent to participate Not applicable.

Consent for publication Not applicable.

Competing interests The authors declare no competing interests.

Open Access This article is licensed under a Creative Commons Attribution 4.0 International License, which permits use, sharing, adaptation, distribution and reproduction in any medium or format, as long as you give appropriate credit to the original author(s) and the source, provide a link to the Creative Commons licence, and indicate if changes were made. The images or other third party material in this article are included in the article's Creative Commons licence, unless indicated otherwise in a credit line to the material. If material is not included in the article's Creative Commons licence and your intended use is not permitted by statutory regulation or exceeds the permitted use, you will need to obtain permission directly from the copyright holder. To view a copy of this licence, visit http://creativecommons.org/licenses/by/4.0/.

\section{References}

Barklund P (1987) Occurrence and pathogenicity of Lophodermium piceae appearing as an endophyte in needles of Picea abies. Trans Br Mycol Soc 89:307-313
Bates D, Maechler M, Bolker B, Walker S (2015) Fitting linear mixedeffects models using lme4. J Stat Softw 67:1-48. https://doi.org/ 10.18637/jss.v067.i01

Carroll G (1988) Fungal endophytes in stems and leaves: from latent pathogen to mutualistic symbiont. Ecology 69:2-9

Carroll G (1995) Forest endophytes: pattern and process. Can J Bot 73(suppl. 1):S1316-S1324

Dotzler M (1991) Infektionsversuche mit Rhizosphaera kalkhoffii und Lophodermium piceae an unterschiedlich gestressten Jungfichten(Picea abies [L.] Karst). Eur J Forest Pathol 21:107-123

Frasz SL, Walker AK, Nsiama TK, Adams GW, Miller JD (2014) Distribution of the foliar fungal endophyte Phialocephala scopiformis and its toxin in the crown of a mature white spruce tree as revealed by chemical and qPCR analyses. Can J for Res 44:1138-1143

Ganley RJ, Sniezko RA, Newcombe G (2008) Endophyte-mediated resistance against white pine blister rust in Pinus monticola. For Ecol Manage 255:2751-2760

Gates DM (1980) Biophysical ecology. Springer, New York

Gourbière F (1988) Structure spatio-temporelle de la mycoflore des premiers stades de decomposition des aiguilles d'Abies alba. Soil Biol Biochem 20:453-458

Jasinski JPP, Payette S (2005) The creation of alternative stable states in the southern boreal forest, Québec, Canada. Ecol Monogr 75:561-583

Lehtijärvi A, Barklund P (2000) Seasonal patterns of colonization of Norway spruce needles by Lophodermium piceae. Forest Pathol 30:185-193

Lehtijärvi A, Swertz C, Barklund P (2001) Co-occurrence of the ascomycete Lophodermium piceae and the rust fungus Chrysomyxa abietis in Norway spruce needles. Forest Pathol 31:25-31

Livsey S, Barklund P (1992) Lophodermium piceae and Rhizosphaera kalkhoffii in fallen needles of Norway spruce (Piceae abies). Eur J for Pathol 22:204-216

McMullin DR, Nguyen HDT, Daly GJ, Menard BS, Miller JD (2018) Detection of foliar endophytes and their metabolites in Picea and Pinus seedling needles. Fungal Ecol 31:1-8

Minter DW (1994) The Rhytismatales on conifers from Europe. In: (Capretti P, Heiniger U, Stephan R eds.) Shoot and foliage diseases in forest trees. Proceedings of a joint meeting of the working parties Canker and shoot blight of conifers (S2.06.02) and Foliage diseases (S2.06.04). Vallombrosa, Firenze, Italy June 6-11, 1994. pp 65-77

Müller MM, Kantola R, Kitunen V (1994) Combining sterol and fatty acid profiles for the characterization of fungi. Mycol Res 98:593-603

Müller MM, Hallaksela A-M (1998) Diversity of Norway spruce needle endophytes in various mixed and pure Norway spruce stands. Mycol Res 102:1183-1189

Müller MM, Valjakka R, Suokko A, Hantula J (2001) Diversity of endophytic fungi of single Norway spruce needles and their role as pioneer decomposers. Mol Ecol 10:1801-1810

Müller MM, Valjakka R, Hantula J (2007) Genetic diversity of Lophodermium piceae in South Finland. Forest Pathol 37:1-10

Müller MM, Hamberg L, Morozova T, Sizykh A, Sieber T (2019) Adaptation of subpopulations of the Norway-spruce-needle endophyte Lophodermium piceae to the temperature regime. Fungal Biol 123:887-894

Osorio M, Stephan BR (1991) Life cycle of Lophodermium piceae in Norway spruce needles. Eur J for Pathol 21:152-163

Oliva J, Ridley M, Redondo MA, Caballol M (2020) Competitive exclusion amongst endophytes determines shoot blight severity on pine. Funct Ecol. https://doi.org/10.1111/1365-2435.13692

Pinheiro J, Bates D, DebRoy S, Sarkar D, R Core Team (2017) nlme: linear and nonlinear mixed effects models. $\mathrm{R}$ package version 3.1-131, URL: https://CRAN.R-project.org/package=nlme 
Quiring D, Adams G, Flaherty L, McCartney A, Miller JD, Edwards $S$ (2019a) Influence of a foliar endophyte and budburst phenology on survival of wild and laboratory-reared eastern spruce budworm, Choristoneura fumiferana on white spruce (Picae glauca). Forests 10:503. https://doi.org/10.3390/f10060503

Quiring D, Flaherty L, Adams G, McCartney A, Miller JD, Edwards $S$ (2019b) An endophytic fungus interacts with crown level and larval density to reduce the survival of eastern spruce budworm, Choristoneura fumigerana (Lepidoptera: Tortricidae), on white spruce (Picea glauca). Can J for Res 49:221-227

Rajala T, Velmala SM, Tuomivirta T, Haapanen M, Müller M, Pennanen T (2013) Endophyte communities vary in the needles of Norway spruce clones. Fungal Biol 117:182-190

R Core Team (2017) R: A language and environment for statistical computing. R Foundation for Statistical Computing, Vienna, Austria. URL https://www.R-project.org/

Scattolin L, Montecchio L (2009) Lophodermium piceae and Rhizosphaera kalkhoffii in Norway spruce: correlations with host age and climatic features. Phytopathologica Mediterranea 48:226-239

Schütt P, Weisgerber H, Lang UM, Roloff A, Stimm B (2006) Enzyklopädie der Holzgewächse. Ecomed Medizin, Verlagsgruppe Hüthig Jehle Rehm GmbH, Germany, Handbuch und Atlas der Dendrologie

Sieber T (1988) Endophytische Pilze in Nadeln von gesunden und geschädigten Fichten (Picea abies (L.) Karsten). Eur J for Pathol 18:321-342

Sieber T (1989) Endophytic fungi in twigs of healthy and diseased Norway spruce and white fir. Mycol Res 92:322-326
Sieber T (2007) Endophytic fungi in forest trees: are they mutualists? Fungal Biol Rev 21:75-89

Stephan BR, Osorio M (1994) Lophodermium piceae and zone lines on spruce needles and in culture. In: Capretti P, Heiniger U, Stephan $\mathrm{R}$ (eds.) Shoot and foliage diseases in forest trees. Proceedings of a Joint Meeting of the Working Parties Canker and Shoot Blight of Conifers (S2.06.02) and Foliage Diseases (S2.06.04). Vallombrosa, Firenze, Italy June 6-11, 1994

Stewart CRA, Doilom M, Taylor JE (2019) Analysis of fungal endophytes in Scottish Sitka spruce plantations shows extensive infections, novel host partners and gives insights into origins. Forest Pathol. https://doi.org/10.1111/efp.12471

Sumarah MW, Miller JD, Adams GW (2005) Measurement of a rugulosin-producing endophyte in white spruce seedlings. Mycologia 97:770-776

Sumarah MW, Kesting JR, Sørensen D, Miller JD (2011) Antifungal metabolites from fungal endophytes of Pinus strobus. Phytochemistry $72: 1833-1837$

Suske J, Acker G (1987) Internal hyphae in young, symptomless needles of Picea abies: electron microscopic and cultural investigation. Can J Bot 65:2098-2103

Suske J, Acker G (1989) Identification of endophytic hyphae of Lophodermium piceae in tissues of green, symptomless Norway spruce needles by immunoelectron microscopy. Can J Bot 67:1768-1774

Warton DI, Hui FKC (2011) The arcsine is asinine: the analysis of proportions in ecology. Ecology 92:3-10

Publisher's note Springer Nature remains neutral with regard to jurisdictional claims in published maps and institutional affiliations. 